\title{
Ophthalmologic disorders in adolescents with type 1 diabetes
}

\section{ABSTRACT}

Chronic complications of diabetes, including damage to the eye, are seen in patients with type 2 diabetes often soon after diagnosis. This type of diabetes is often diagnosed after a long period of unrecognized and untreated disease. Type 1 diabetes is one of the most common metabolic diseases diagnosed in children, and is associated with the risk of developing multiple chronic complications. Diabetic eye disease can be associated with abnormalities in various eye structures. It should be remembered that early changes in the organ of vision may not give clear clinical symptoms. Their detection requires the use of modern diagnostic methods, which also allow early detection of changes that threaten damage to the eye. The degree of metabolic control, the presence of dyslipidemia, as well as micro- and macroangiopathy affect the development of chronic complications, including changes in the eye. Damage to small blood vessels leads to changes in retinal perfusion and to macular edema. As a result of these changes, diabetic retinopathy develops. Early diagnosis of the above complications allows prevention of their development. (Clin Diabetol 2020; 9; 6: 485-488)

Key words: diabetic cataract, diabetic retinopathy, intraocular pressure, metabolic control, type 1 diabetes, visual impairment

Address for correspondence:

Aleksandra Pilśniak

Inpatient Department of Radiation

and Clinical Oncology

Maria Skłodowska-Curie Institute - Oncology Center

Wybrzeże Armii Krajowej 15

44-102 Gliwice, Poland

e-mail: dudek.ola@op.pl

Clinical Diabetology 2020, 9; 6: 485-488

DOI: $10.5603 /$ DK.2020.0050

Received: 27.07 .2020

Accepted: 02.11.2020

\section{Introduction}

In diabetes mellitus, first described by John Rollo in 1798 , vision complications often occur. The history of diabetes goes back to ancient times. The first reports date back to 3500 B.C.E. and come from ancient Egypt. The term 'diabetes', which in Greek meant 'siphon' and 'water flowing through the body', was first used by Areteus of Cappadocia (30-90 CE). He was also the first to provide a full clinical description of diabetes. In 1889, Minkowski and von Mering proved that there is a correlation between diabetes and the islets of Langerhans. Insulin discovery in 1922 by Banting, Macleod, Best, and Collip was of breakthrough significance [1-3]. Chronic complications in patients with type 2 diabetes, including damage to the eye, are often seen soon after diagnosis. This type of diabetes is often diagnosed after a long period of unrecognized and untreated disease $[4,5]$. In type 1 diabetes, anatomical changes in the eye usually appear after a longer duration of diabetes. Descriptions of eye complications in adolescent diabetic patients have a long history [6-9]. In the past, these complications were common due to difficulties in balancing glucose metabolism. Long-term studies on the relationship between the level of glucose control reflected by the examination of $\mathrm{HbA}_{1 \mathrm{c}}$ levels and diabetic retinopathy in juvenile patients with type 1 diabetes have been recently presented by Swedish authors [10]. Other authors have also presented the results of similar studies [11-13]. A comprehensive discussion of recommendations for the diagnosis and treatment of ophthalmologic complications in diabetes is presented in the recommendations of the Diabetes Poland [14]. According to these recommendations, the first ophthalmological examination should be performed at diagnosis in patients with type 2 diabetes, and for type 1 diabetes patients, such examination is usually performed after 5 years of the disease. During 
puberty, adolescents usually have their first examination earlier. The main reason for the development of complications is chronic hyperglycemia with high concentration of glycated hemoglobin. In addition, it should be remembered that apart from anatomical complications associated with lens opacities and vascular changes in diabetes, there may also be certain functional complications resulting from acute disorders of glycemic homeostasis. These symptoms often occur at the onset of the disease in patients with type 1 diabetes and are the result of glucose homeostasis disorders. Visual disturbances can be a consequence of both hyperglycemia and hypoglycemia. Hyperglycemia causes an increase in osmotic pressure and refractive disorders, whereas in hypoglycemia, glucose delivery to photoreceptors is reduced. Visual disturbances associated with lens refractive disorders often occur when type 1 diabetes is diagnosed. They are a consequence of frequently elevated glucose levels in blood and aqueous humor at that time. Blood glucose control usually resolves the symptoms.

\section{Cataract}

The cataract is manifested by the clouding of the lens of the eye, and is one of the pre-existing chronic complications of diabetes. Its prevalence in type 1 diabetes is estimated to be around $10 \%$, and in type 2 diabetes the percentage is higher. Bilateral cataracts, which appear as the first symptom of diabetes and lead to its diagnosis, are unusual and only a few such cases have been described in the literature [15]. There are juvenile cataracts and cataracts in adults. In type 1 diabetes, there is often a snowflake cataract characterized by fine haze that may be present in the cortex or around the anterior and posterior lens capsule [16]. The only effective way to improve vision in people affected by this disease is to remove the cloudy cornea and implant an artificial lens in its place. Changes in the fundus manifesting as diabetic macular edema (DME) may be yet another vision disorder in diabetes. Diabetic maculopathy may be associated with cataract surgery because the latter often accelerates or intensifies diabetic macular edema (DME) [17]. Chronic hyperglycemia, leading to the production of inflammatory cytokines and leukocyte adhesion, is important in the development of this condition. What is more, capillaries in the central part of the retina become narrower and ischemia leads to the disappearance of pericytes and damage to the endothelium of small blood vessels. The vessel wall is damaged and micro-aneurysms are formed. Damage to the vascular wall and increased blood viscosity lead to retinal hypoxia and retinal exudate. As a result of the weakened vessel wall being ruptured, blood strokes ap- pear inside the eye. Datta et al. observed four important clinical features in five children with newly diagnosed diabetes who developed early cataracts. These features include the prolonged duration of symptoms before diagnosis, high $\mathrm{HbA} 1$ levels at diagnosis, a clear predominance of girls and the age of puberty [18]. The possibility of using modern diagnostic methods allows early detection of changes that threaten eye damage $[19,20]$. Through optical coherent tomography (OCT) we can assess the condition of the macula and optic disc. Fluorescein angiography is a method which accurately locates the sites of leakage of diseased vessels and ischemia zones, and OCT angiography allows us to accurately visualize vascular changes without the need for contrast agents. In addition, there are a number of other methods that allow accurate diagnosis of lesions within the eye at an early stage of their development [21-23]. Recently, Chinese authors have presented results of their research on the thickness of choroid, optic disc, and macular thickness in children with type 1 diabetes [24]. Other authors have also drawn attention to the need to use modern diagnostic methods for early detection of changes in the organ of vision in adolescent diabetic patients [25].

\section{Diabetic retinopathy}

Diabetic retinopathy is estimated to be the most common complication of diabetes and can lead to complete blindness. In a study by Wang et al. [26], $20.1 \%$ of 2,240 subjects with type 1 diabetes and $7.2 \%$ of 1,768 subjects with type 2 diabetes developed retinopathy over a median follow-up period of 3.2 and 3.1 years, respectively. Moreover, Kernell et al. [27] found that in children and adolescents with insulin-dependent diabetes, retinopathy was diagnosed in $6 \%$ and $18 \%$ of patients in pubertal stages one and five, respectively. The cause of diabetic retinopathy is microangiopathy, which is damage to small blood vessels, which leads to damage to the retina itself. Recently, an analysis of retrospective studies has been presented, which suggested that genetic conditions may have an impact on the development of diabetic retinopathy [28]. However, according to the authors of this study, this requires further research, and a greater number of patients, especially children with type 1 diabetes without known visual impairment and diabetic retinopathy. Results of studies on the relationship between the occurrence of atherosclerotic changes in the carotid arteries and the occurrence of diabetic retinopathy have been presented [29]. In the group of patients with type 1 diabetes free from cardiovascular diseases, an ultrasound of carotid arteries was performed, the results of which were compared with the incidence and severity of diabetic 
retinopathy. Advanced stages of diabetic retinopathy have been shown to indicate an increased risk of carotid atherosclerosis. German authors have pointed out the coexistence of chronic macro- and microvascular complications, including retinopathy, in young children with type 1 diabetes [30]. In addition, they have highlighted the need for prevention in early type 1 diabetes to reduce the significant risk of complications and comorbidities at an early age. The appearance of other chronic complications may be the first sign of changes in the eye. Malerbi et al. have pointed out that very accurate diagnostic methods allow us to detect changes in retinal perfusion in patients with normal fundus [31]. Fluorescein angiography is indicated in patients with impaired renal glomerular filtration. There are three stages of diabetic retinopathy - non-proliferative retinopathy, pre-proliferative retinopathy, and proliferative retinopathy. This classification does not include maculopathy, which can occur at any stage of retinopathy. Recently, there have been a number of reports on the assessment of the degree of morphological changes in the retina in adolescent patients with type 1 diabetes [32-34]. Important risk factors for the development of retinopathy are lipid disorders, obesity, hypertension, frequent infections, blood clotting disorders, and anemia. People who develop other late complications in diabetes, such as diabetic nephropathy, are at risk. An extensive report has been published regarding the occurrence of changes in the organ of vision in patients with type 1 and type 2 diabetes, based on the analysis of the frequency of changes in patients in north-eastern Poland. Of the respondents, 26\% were patients with type 1 diabetes and $74 \%$ were patients with type 2 diabetes. Diabetic retinopathy was found in $25.48 \%$ of subjects. In patients with type 1 diabetes, $32.58 \%$ of cases were diagnosed with non-proliferative diabetic retinopathy, while in $24.44 \%$ of cases, patients developed proliferative retinopathy [35]. The authors believe that the results obtained may reflect the degree of diabetes care. Future research should focus on preventing diabetic complications in young patients and explaining the above connections.

\section{Conclusions}

Recently, there has been a report in Polish literature discussing the results of eye examinations in adolescent patients with type 1 diabetes. These results confirm that it is necessary to use modern diagnostic methods for the early detection of ocular complications in adolescent patients [25, 31]. It should be remembered that early changes in the organ of vision may not give clear clinical symptoms, and their detection requires the use of modern diagnostic methods. It is very important to make diabetologists dealing with adolescent patients aware of the need to intensify these tests in adolescent patients, and refer these patient for ophthalmologist consultations.

\section{Conflict of interests}

The authors declare to have no conflict of interests.

\section{REFERENCES}

1. Matuszewski W, Bandurska-Stankiewicz E, Modzelewski R, et al. Diagnosis and treatment of diabetic retinopathy - historical overview. Clinical Diabetology. 2017; 6(5): 182-188, doi: 10.5603/ dk.2017.0030.

2. Polonsky KS. The past 200 years in diabetes. N Engl J Med. 2012; 367(14): 1332-1340, doi: 10.1056/NEJMra1110560, indexed in Pubmed: 23034021.

3. Watkins P. Evolution of diabetes care over half a century. Clin Med (Lond). 2007; 7(2): 109-113, doi: 10.7861/clinmedicine.7-2-109, indexed in Pubmed: 17491493.

4. Otto-Buczkowska E, Chwalba A. Prediabetes - it is a very important and still not solved the problem! Forum Medycyny Rodzinnej. 2017; 11(4): 107-112, doi: 1.

5. Dudek A, Otto-Buczkowska E. Can type 2 diabetes be cured? IJSRM Human. 2020; 15 (2): 304-310.

6. Ehrlich RM, Kirsch S, Daneman D. Cataracts in children with diabetes mellitus. Diabetes Care. 1987; 10(6): 798-799, doi: 10.2337/ diacare.10.6.798, indexed in Pubmed: 3428060.

7. Falck A, Laatikainen L. Diabetic cataract in children. Acta Ophthalmol Scand. 1998; 76(2): 238-240, doi: 10.1034/j.16000420.1998.760223.x, indexed in Pubmed: 9591961.

8. Martín Carballo G, Peralta Calvo J, Alonso Criado S, et al. Bilateral cataract in the initial phase of insulin dependent diabetes mellitus in childhood. An Esp Pediatr. 1993; 39(5): 453-454, indexed in Pubmed: 8285465.

9. Otto-Buczkowska E, Szumilas K, Sońta-Jakimczyk D. Eye changes in children with diabetes. Pol Tyg Lek. 1971; 26(28): 1065-1067, indexed in Pubmed: 5096673.

10. Andreasson R, Ekelund C, Landin-Olsson M, et al. HbA1c levels in children with type 1 diabetes and correlation to diabetic retinopathy. J Pediatr Endocrinol Metab. 2018; 31(4): 369-374, doi: 10.1515/jpem-2017-0417, indexed in Pubmed: 29494341.

11. Hautala N, Siiskonen M, Hannula V, et al. Early glycaemic control for maintaining visual function in type 1 diabetes: The Oulu cohort study of diabetic retinopathy. Eur J Ophthalmol. 2018; 28(6): 684-689, doi: 10.1177/1120672117750053, indexed in Pubmed: 29554811.

12. Öberg D, Salemyr J, Örtqvist E, et al. A longitudinal study of serum insulin-like growth factor-I levels over 6 years in a large cohort of children and adolescents with type 1 diabetes mellitus: A marker reflecting diabetic retinopathy. Pediatr Diabetes. 2018; 19(5): 972-978, doi: 10.1111/pedi.12681, indexed in Pubmed: 29663652.

13. Virk SA, Donaghue KC, Cho YHi, et al. Association between HbA1c variability and risk of microvascular complications in adolescents with type 1 diabetes. J Clin Endocrinol Metab. 2016; 101(9): 3257-3263, doi: 10.1210/jc.2015-3604, indexed in Pubmed: 27186858.

14. 2020 Guidelines on the management of diabetic patients. Clinical Diabetology. 2020; 9(1): 48-51.

15. Pakhetra R, Jyotsna VP. Bilateral early cataracts in type 1 diabetes. Med J Armed Forces India. 2009; 65(1): 71-72, doi: 10.1016/ S0377-1237(09)80063-4, indexed in Pubmed: 27408198.

16. Ehrlich RM, Kirsch S, Daneman D. Cataracts in children with diabetes mellitus. Diabetes Care. 1987; 10(6): 798-799, doi: 10.2337/ diacare.10.6.798, indexed in Pubmed: 3428060. 
17. Boscia F, Giancipoli E, D'Amico Ricci G, et al. Management of macular oedema in diabetic patients undergoing cataract surgery. Curr Opin Ophthalmol. 2017; 28(1): 23-28, doi: 10.1097/ ICU.0000000000000328, indexed in Pubmed: 27661663.

18. Datta V, Swift PG, Woodruff GH, et al. Metabolic cataracts in newly diagnosed diabetes. Arch Dis Child. 1997; 76(2): 118-120, doi: 10.1136/adc.76.2.118, indexed in Pubmed: 9068299.

19. De Benedetto U, Querques G, Lattanzio R, et al. Macular dysfunction is common in both type 1 and type 2 diabetic patients without macular edema. Retina. 2014; 34(11): 2171-2177, doi: 10.1097/IAE.0000000000000205, indexed in Pubmed: 24978668.

20. Srinivasan S, Dehghani C, Pritchard N, et al. Ophthalmic and clinical factors that predict four-year development and worsening of diabetic retinopathy in type 1 diabetes. J Diabetes Complications. 2018; 32(1): 67-74, doi: 10.1016/j.jdiacomp.2017.09.002, indexed in Pubmed: 29097055.

21. Gerendas BS, Hatz K, Kaider A, et al. Ganglion cell layer thickening in well-controlled patients with type 1 diabetes: an early sign for diabetic retinopathy? Acta Ophthalmol. 2020; 98(3): e292-e300, doi: 10.1111/aos.14273, indexed in Pubmed: 31654495.

22. Stem MS, Dunbar GE, Jackson GR, et al. Glucose variability and inner retinal sensory neuropathy in persons with type 1 diabetes mellitus. Eye (Lond). 2016; 30(6): 825-832, doi: 10.1038/ eye.2016.48, indexed in Pubmed: 27034201.

23. Tekin K, Inanc M, Kurnaz E, et al. Quantitative evaluation of early retinal changes in children with type 1 diabetes mellitus without retinopathy. Clin Exp Optom. 2018; 101(5): 680-685, doi: 10.1111/cxo.12667, indexed in Pubmed: 29488254.

24. Li T, Jia $Y$, Wang $S$, et al. Change in peripapillary and macular choroidal thickness change in children with type 1 diabetes mellitus without visual impairment or diabetic retinopathy. Acta Ophthalmol. 2020; 98(2): e203-e211, doi: 10.1111/aos.14225.

25. Kołodziej M, Waszczykowska A, Korzeniewska-Dyl I, et al. The HDOCT study may be useful in searching for markers of preclinical stage of diabetic retinopathy in patients with type 1 diabetes. Diagnostics (Basel). 2019; 9(3), doi: 10.3390/diagnostics9030105, indexed in Pubmed: 31454902.

26. Wang SY, Andrews CA, Herman WH, et al. Incidence and risk factors for developing diabetic retinopathy among youths with type 1 or type 2 diabetes throughout the United States. Ophthalmology. 2017; 124(4): 424-430, doi: 10.1016/j.ophtha.2016.10.031, indexed in Pubmed: 27914837.
27. Kernell A, Dedorsson I, Johansson B, et al. Prevalence of diabetic retinopathy in children and adolescents with IDDM. A populationbased multicentre study. Diabetologia. 1997; 40(3): 307-310, doi: 10.1007/s001250050679, indexed in Pubmed: 9084969.

28. Broadgate S, Kiire C, Halford S, et al. Diabetic macular oedema: under-represented in the genetic analysis of diabetic retinopathy. Acta Ophthalmol. 2018; 96 Suppl A111: 1-51, doi: 10.1111/ aos.13678, indexed in Pubmed: 29682912.

29. Carbonell M, Castelblanco E, Valldeperas $X$, et al. Diabetic retinopathy is associated with the presence and burden of subclinical carotid atherosclerosis in type 1 diabetes. Cardiovasc Diabetol. 2018; 17(1): 66, doi: 10.1186/s12933-018-0706-z, indexed in Pubmed: 29728117.

30. Tönnies T, Stahl-Pehe A, Baechle C, et al. Risk of microvascular complications and macrovascular risk factors in early-onset type 1 diabetes after at least 10 years duration: an analysis of three population-based cross-sectional surveys in Germany between 2009 and 2016. Int J Endocrinol. 2018; 2018: 7806980, doi: 10.1155/2018/7806980, indexed in Pubmed: 29808091

31. Malerbi FK, Regatieri CV, de Sa JR, et al. Retinal malperfusion in albuminuric Type 1 diabetes mellitus patients without clinical signs of diabetic retinopathy: a prospective pilot study. Int J Retina Vitreous. 2017; 3: 49, doi: 10.1186/s40942-017-0102-y, indexed in Pubmed: 29270314.

32. Gołębiewska J, Olechowski A, Wysocka-Mincewicz M, et al. Choroidal thickness and ganglion cell complex in pubescent children with type 1 diabetes without diabetic retinopathy analyzed by spectral domain optical coherence tomography. J Diabetes Res. 2018; 2018: 5458015, doi: 10.1155/2018/5458015, indexed in Pubmed: 29850607.

33. Melvin A, Redahan L, Hatunic M, et al. Microvascular diabetes complications in a specialist young adult diabetes service. Ir J Med Sci. 2019; 188(1): 129-134, doi: 10.1007/s11845-018-1827-9, indexed in Pubmed: 29732503.

34. Ruiz-Ocaña $P$, Espinoza Requena $P$, Alonso-Ojembarrena $A$, et al. Decreased retinal thickness in type 1 diabetic children with signs of nonproliferative diabetic retinopathy. Int J Endocrinol. 2018; 2018: 1078531, doi: 10.1155/2018/1078531, indexed in Pubmed: 29853875.

35. Matuszewski W, Baranowska-Jurkun A, Stefanowicz-Rutkowska MM, et al. Prevalence of diabetic retinopathy in type 1 and type 2 diabetes mellitus patients in north-east Poland. Medicina (Kaunas). 2020; 56(4), doi: 10.3390/medicina56040164, indexed in Pubmed: 32268561. 